\title{
MESTRADOS PROFISSIONAIS NA ÁREA DE EDUCAÇÃO E ENSINO
}

\author{
Clarilza Prado de Sousa (PUCSP)* \\ Vera Maria de Souza Placco (PUCSP)**
}

\begin{abstract}
RESUMO
O texto procura discutir dois dos desafios que programas de Mestrado Profissional (MP) enfrentam atualmente, para constituir uma identidade funcional que os distinga dos mestrados acadêmicos e mantenham a qualidade acadêmica desejável. Partimos do pressuposto que os MP têm um compromisso com um impacto mais preciso em relação à educação básica, respondendo à sua realidade e demandas, e que sua proposição deve estar alinhada com os resultados de uma política voltada para a melhoria da qualidade do ensino. Assim, procura-se contribuir para o delineamento das necessidades e compromisso educacional que um MP deve atender. $\mathrm{O}$ primeiro desafio destes MP diz respeito à interpretação que têm feito das necessidades do contexto educacional para definir suas propostas. O segundo diz respeito às possibilidades de como formar o professor. Considerando os fundamentos consolidados da área de formação, é possível ultrapassar as disputas entre comunidades epistêmicas, propondo uma formação completa e complexa do profissional da educação.
\end{abstract}

Palavras-chave: Mestrado profissional. Formação de professores. Teoria da formação.

\begin{abstract}
PROFESSIONAL MASTERS IN THE FIELD OF EDUCATION AND TEACHING

The text discusses two of the challenges that Professional Master's programs (PM) currently face. We assume that the PM have a commitment to a clear impact, regarding basic education, responding to its reality and demands, and that its proposal should be aligned with the results of a policy for improving the quality of education. So, we seek to contribute to the educational guidelines that a PM should commit. The first challenge of the PM concerns the interpretation that has been made of the needs of the educational context to define its proposals. The second challenge concerns the interpretation that has been done on how to form the teacher. The teacher education field considers the complexity of the professional practice of education and does not minimize their formation needs and conditions. To consider the consolidated
\end{abstract}

* Doutora em Currículo pela Pontifícia Universidade Católica de São Paulo (PUCSP). Professora Titular dos Programas de Estudos Pós-Graduados em Educação: Psicologia da Educação e Educação: Formação de Formadores da PUC-SP. E-mail: clarilza.prado@uol.com.br

** Doutora em Psicologia da Educação pela Pontifícia Universidade Católica de São Paulo (PUCSP). Professora Titular dos Programas de Estudos Pós-Graduados em Educação: Psicologia da Educação e Educação: Formação de Formadores da PUC-SP. E-mail: veraplacco@pucsp.br 
basis of the education field, will allow to overcome the disputes between epistemic communities, each seeking to highlight their own perspective and knowledge, by proposing a complete and complex formation of the education professional.

Keywords: Professional master. Teacher formation. Theory of teacher formation.

\section{RESUMEN}

\section{MAESTRIAS PROFESIONALES EN LA ÁREA DE EDUCACIÓN Y ENSEÑANZA}

El texto analiza dos de los retos que los programas de Maestrías Profesionales (MP) enfrentan en la actualidad, para construir una identidad funcional que los distingua de las maestrias académicas y mantenga la calidad académica deseable. Partimos del presupuesto que los MP tienen un compromiso con un impacto más preciso con respecto a la educación básica, en respuesta a su realidad y demandas, y que su propuesta debe estar alineada con los resultados de una política de mejora de la calidad de la educación. De este modo, se busca contribuir al diseño de las necesidades y el compromiso educativo que debe cumplir un MP. El primer desafío de los MP se refiere a la interpretación que han hecho de las necesidades del contexto educativo para definir sus propuestas. El segundo se refiere a las posibilidades de cómo formar el maestro. Teniendo en cuenta los fundamentos consolidados del area de formaciòn, es posible superar los conflictos entre las comunidades epistémicas, proponiendo una formación completa y compleja del profesional de la educación.

Palabras claves: Maestría profesional. La formación del profesorado. La teoria de la formación.

\section{Introdução: discussão de orientações básicas}

Os mestrados profissionais na área de Educação iniciaram em 2009, mas, efetivamente, se intensificaram a partir de 2010. Hoje estão credenciados na Capes mais de 33 programas de Mestrado Profissional (MP).

Discutimos, neste texto, alguns dos grandes desafios que estes programas enfrentam para constituir sua identidade funcional, que os distinga dos mestrados acadêmicos e mantenham a qualidade necessária. Partimos do pressuposto de que tais mestrados têm um compromisso com um impacto mais claro, mais preciso, em relação à educação básica, respondendo à sua realidade e demandas, e que sua proposição deve estar alinhada com os resultados de uma política voltada para a melhoria da qualidade do ensino, principalmente da formação de professores, coordenadores e diretores de escola.

Não se discute a importância dos mestrados acadêmicos e a missão que têm de formar pesquisadores voltados para o desenvolvimento dos temas relevantes da educação; apenas procura-se contribuir para o delineamento das necessidades que um mestrado profissional deve atender, procurando assim contribuir para o compromisso educacional que deve assumir.

$\mathrm{O}$ primeiro desafio desses MPs diz respeito à interpretação que têm feito das necessidades do contexto educacional para definir suas propostas. Como suas propostas compreendem as necessidades da educação? Há que se dizer que tantas são as necessidades da educação que, qualquer que seja a proposta, estará sempre atendendo a uma das dificuldades, a um dos problemas enfrentados pela educação. Parece mesmo que isto justificaria que muitos programas até agora propostos não apresentem uma direção única. No entanto, se diz também que, ao tentar atender a alguma das dificuldades da educação, perde-se em especificidade e pode não se atender realmente às prioridades, caindo-se na generalização amorfa e ineficaz. 
No entanto, entendemos que é fundamental que essas propostas possibilitem analisar as dificuldades da educação básica, tendo em vista a realidade vigente nesse nível de ensino e não apenas - como é frequente acontecer - levando em conta os reflexos deste nível de ensino no ensino superior, isto é, considerando a dificuldade dos alunos que chegam atualmente à universidade. As dificuldades que alunos apresentam ao chegarem ao ensino superior vão muito além dos problemas da escola básica. Muitas dos problemas do ensino superior se explicam pelas próprias condições que são encontradas no próprio ensino superior, principalmente por este não ter adequado seu ensino, durantes décadas; por não considerar que este jovem do ensino superior é bem diferente daquele que a maioria dos atuais professores foi um dia. As mudanças tecnológicas, o contexto social, os processos de comunicação criaram outras perspectivas e possibilidades ao jovem universitário; somente o ensino continua, na maioria das vezes, igual. Acresce-se a isto o fato das Instituições de Ensino Superior não realizarem mudanças curriculares que permitiriam recuperar a defasagem de alunos que apresentam dificuldades em sua escolaridade.

Acredita-se que o desenvolvimento de propostas de MPs na área de educação e ensino deveriam considerar no mínimo duas orientações fundamentais. A primeira orientação seria que as propostas de mestrado profissional levassem em conta os diagnósticos do sistema de ensino. Existem hoje muitas fontes de informações sobre o ensino - de todos os níveis - que não podem ser desconsideradas. Programas de MPs, compromissados com a formação de profissionais que possam promover impacto na escola, precisam considerar os diagnósticos que permitem identificar os problemas mais significativos que o ensino fundamental e médio apresenta. As avaliações externas nacionais, como o Sistema de Avaliação da Educação Básica (SAEB) e a Prova Brasil, e as avaliações estaduais, realizadas pelas Secretarias de Educação, podem oferecer elementos importantes de compreensão da realidade da educação básica. Além disso, é necessário considerar que pesquisas feitas na área de educação vêm há anos pautando estas discussões e, portanto, precisariam ser analisadas pelos proponentes de MPs.
A segunda orientação fundamental que precisaria ser observada na proposição de MPs voltados para formação de profissionais da área de educação refere-se às teorias e aos resultados de pesquisas sobre formação de educador. Teorias, estudos e pesquisas consolidados são realizados internacionalmente e também no Brasil, e pode-se afirmar que a área de formação de professores conta hoje com uma sólida fundamentação, que permite subsidiar a formação de professor, diretor, coordenador, supervisor de ensino. É uma área que considera a complexidade da atuação do profissional da educação e que, portanto, não minimiza suas necessidades e condições de formação. Considerar os fundamentos teóricos e as pesquisas sobre formação de educador possibilita ultrapassar as disputas entre comunidades epistêmicas que procuram, cada uma delas, tornar mais relevante sua perspectiva e seus saberes, disputas essas em detrimento de uma formação completa e complexa do profissional da educação.

\section{Discutindo a primeira orientação}

Propor um MP em educação implica identificar quem são estes professores e gestores que estão hoje atuando no sistema de ensino. Uma breve consulta ao QEdu, a maior plataforma de dados sobre a educação, que reúne os dados do última Prova Brasil, em que foram aplicados questionários com 152 perguntas acerca de 300 mil professores, permite traçar um perfil das condições socioeconômicas e das condições de trabalho, práticas pedagógicas e percepção sobre o aprendizado dos alunos. Alguns dos dados importantes observados é que a maioria dos professores consultados teve licenciatura específica em matemática e letras e $34 \%$ se formaram entre 3 a 7 anos e $28 \%$, de 8 a 14 anos, o que permite afirmar que não é o tempo da formação inicial que estaria criando dificuldades no desempenho do professor. Tais dados indicam também que seria necessário verificar a própria formação inicial que vem sendo oferecida. Os estudos realizados por Gatti, Barreto e André (2011) já têm indicado os problemas desta formação dos professores. Conclusão imediata possível é a de que um MP que oferecesse a reprodução do modelo de curso de graduação não prepararia o professor 
para o desempenho esperado na Educação Básica.

A análise das dificuldades desses professores deve considerar também os estudos realizados por quase cinco mil teses e dissertações produzidas somente na área de educação, na área de formação de professores, e as inúmeras pesquisas realizadas por grupos de pesquisa consolidados na área de educação. Estes estudos e teses têm, muitos deles, feito análises consistentes do desempenho docente e revelado os pontos a serem enfatizados em processos de formação, de aperfeiçoamento, de correção de trajetória necessária aos docentes.

Portanto, a proposição de um MP que não considera os diagnósticos, seja das avaliações de larga escala, seja das pesquisas produzidas pela área de educação, acaba por reproduzir erros já apontados da formação inicial e não levam a ação do MP a atuar realmente no ponto exigido.

Os dados disponíveis permitem ainda se ter uma avaliação por região e estado, favorecendo o desenvolvimento de propostas contextualizadas, $o$ que permitiria focalizar mais claramente as dificuldades dos docentes e gestores educacionais, alvos de determinado programa.

Se, por um lado, é fundamental que os dados de avaliação e pesquisa orientem a elaboração das propostas de MP, por outro, seria recomendável que estas propostas estabelecessem para os seus futuros alunos disciplinas que os habilitassem a ler, analisar e interpretar os dados das avaliações existentes. Estudos realizados (SOUSA et al, 2012), têm revelado o profundo desconhecimento dos dados de avaliação por professores que lecionam na Educação Básica. Estes não utilizam os dados encaminhados pelas secretarias estaduais e, portanto, têm dificuldades de identificar os principais problemas que seus alunos vêm enfrentando. Pesquisas realizadas sobre dificuldades recorrentes apresentadas pelos alunos de $5^{\circ}$ série, ao longo de seis anos de avaliações de larga escala, com professores de um sistema de ensino, revelaram que professores que não utilizam os dados das avaliações constroem representações que não ajudam a superar as dificuldades dos alunos (SOUSA et al, 2012).

O professor constrói representações que permitem amenizar o conflito da não aprendizagem revelado nos resultados das avaliações em larga escala, tais como: falta de apoio da família; pouco tempo; formação universitária insuficiente; ausência de material didático; pressão administrativa para a não reprovação; a sua imagem que vem sendo incessantemente desconstruída pela mídia (SANTOS, 2014). Essas representações se constituem como um discurso anônimo, que respondem a toda e qualquer dificuldade e não evidenciam implicações pessoais subjetivas com o processo de aprendizagem (SOUSA et al, 2012).

$\mathrm{O}$ que se pretende afirmar com essa primeira orientação é que, considerando o grande volume de diagnósticos de larga escala na área de educação e as pesquisas significativas da área, não é possível que se tomem decisões de propostas de MP na área de educação e ensino que não levem em consideração os caminhos apontados pelos dados colocados à disposição do planejador. As propostas de MP de educação e ensino precisam considerar os resultados das pesquisas sobre a temática, precisam focar a atenção nos aspectos considerados mais relevantes a serem corrigidos e desenvolvidos, garantindo, assim, economia de recursos e melhores resultados nos processos formativos.

\section{Discutindo a segunda orientação}

Há proposições e questionamentos teóricos em relação à formação de professores. Pergunta-se frequentemente: que saberes são necessários ao exercício docente? Quais desses saberes têm sido enfocados nos diferentes processos formativos? Com que finalidade seriam eles trabalhados na formação de professores? Com que resultados? Constatam-se, com frequência, muitas dificuldades e limitações desses processos formativos, mas especialmente os resultados pouco significativos que alcançam.

As experiências e teorias sobre formação de educadores têm deixado claro a necessidade de considerar nesta formação a diversidade de dimensões que a atuação do professor envolve, de modo que o desenvolvimento profissional do professor se realize nessa multiplicidade, uma vez que se entende que esta ocorra necessariamente no próprio sujeito.

Assim, o que se propõe é que a formação de professores deve envolver o planejamento de atividades que atinjam um conjunto de dimensões, que estão sempre presentes no ser humano e que 
são passíveis de desenvolvimento intencional e consciente, seja por parte do formador, seja por parte do formando. Considera-se, assim, que essas dimensões estão intrinsecamente engendradas com a intencionalidade e a consciência do formador e dos formandos.

Nesse contexto, foca-se aqui a aprendizagem do adulto professor que se forma em um programa de MP para discutir os processos que estão envolvidos na formação de professores, de coordenadores, de gestores e que devem ser considerados no planejamento destes mestrados profissionais.

\section{As dimensões da formação de professores}

O ser humano se constitui de múltiplas dimensões, sincronicamente engendradas, e, se estas não forem assim consideradas nos processos formativos, muitos dos objetivos propostos nesses processos não serão atingidos e, portanto, não haverá resultados ou repercussões no próprio sujeito e em sua prática cotidiana.

Os textos que têm apresentado os conceitos e proposições sobre o tema (PLACCO, 2002a, 2002b, 2002c, 2006, 2008) chamam atenção para os conceitos de sincronicidade ${ }^{1}$, de multidimensionalidade sincrônica da formação e do trabalho de professores, ressaltando, além disso, a necessidade da consciência do professor ao longo do processo formativo e de sua prática docente, o que possibilitará sua maior participação e compromisso com a docência e com a própria formação. No processo de formação, o movimento de desenvolvimento profissional do professor deve considerar que a aprendizagem dos novos conhecimentos é origem e consequência desse movimento de desenvolvimento que é provocado pela sincronicidade de desenvolvimento de diferentes dimensões.

A proposição dessas dimensões foi se constituindo durante longos anos de estudo e atividades de formação de educadores. Pode-se afirmar que, ao longo do tempo, essas dimensões foram ganhando

\footnotetext{
1 Sincronicidade é entendida por Placco (2002, p. 18) como "ocorrência crítica de componentes políticos, humano-interacionais e técnicos", e estes "se traduzem em movimento que é ação de e entre professor-aluno-realidade". Assim, entende-se a formação e o trabalho docente como compreendendo essa multidimensionalidade sincrônica.
}

clareza, especificidade e amplitude em sua aplicação à docência e à formação de professores. Assim, está consolidado entre os que pesquisam a formação de docentes, no Brasil e em outros países, que há necessidade de que os formadores e formandos tenham conhecimento e consciência das dimensões e dos saberes, nos processos formativos e em sua prática cotidiana (GARCIA, 1999; GATTI, 1996, 2000; GATTI; BARRETO; ANDRÉ, 2011; NÓVOA, 1992; OLIVEIRA, 2011; PERRENOUD, 1993; PINEAU, 2004; SCHÖN, 1992; TARDIF; LESSARD, 2005).

Apresenta-se e discute-se, neste texto, o conjunto das dimensões que estão envolvidas no processo de formação e que foram organizadas por Placco (2006, 2008). Evidentemente, em cursos de formação de professores, coordenadores e gestores, todas estas dimensões devem ser contempladas, assim como em programas de MP, em que se busca a formação de formadores e em que é necessário ter claro que o desenvolvimento somente em uma das dimensões, como, por exemplo, a dos conteúdos básicos de cada disciplina ou área de atuação, não forma o professor, não habilita o coordenador a orientar professores e não possibilita ao gestor dirigir uma escola. Como dito, os saberes básicos de cada área devem estar articulados com os saberes da docência, da educação e com os saberes psicossociais, para que um formando, candidato a professor, ou um coordenador pedagógico ou ainda um gestor de escola alcance sua profissionalidade na área de educação. O que chama atenção, quanto à sincronicidade das múltiplas dimensões da profissionalidade do educador, é que as Instituições de Ensino Superior não podem, na defesa de uma área de atuação ou de um grupo epistêmico, considerar que realizem a formação de profissionais de educação, oferecendo apenas a possibilidade de domínio de um única dimensão dos saberes. A perspectiva da sincronicidade indica que, quaisquer que sejam as dimensões consideradas, devem estar articuladas, quando se pensa em formação de professores. É verdade que assim também não se formam coordenadores e gestores, se estes não aprenderem a articular os saberes pedagógicos e psicossociais com os saberes disciplinares; também não se formam 
professores se estes não conseguirem articular os conteúdos de uma determinada área disciplinar com os saberes pedagógicos e psicossociais que são exigidos para sua atuação em sala de aula.

Não se formam professores se eles não conseguirem articular os conteúdos de uma determinada área disciplinar com os saberes pedagógicos e psicossociais que são exigidos para sua atuação em sala de aula, assim como não se formam coordenadores e gestores se eles não aprenderem a articular os saberes pedagógicos e psicossociais com os saberes disciplinares.

Considera-se que essa é uma diretriz que deve ser clara tanto para a formação de professores na graduação, quanto na pós-graduação, nos mestrados profissionais ou acadêmicos.

Para oferecer uma imagem de cada uma das dimensões que se articulam sincronicamente na docência, Placco (2014) as reuniu e as apresenta na Figura 1.

Figura 1 - Dimensões que se articulam sincronicamente na docência

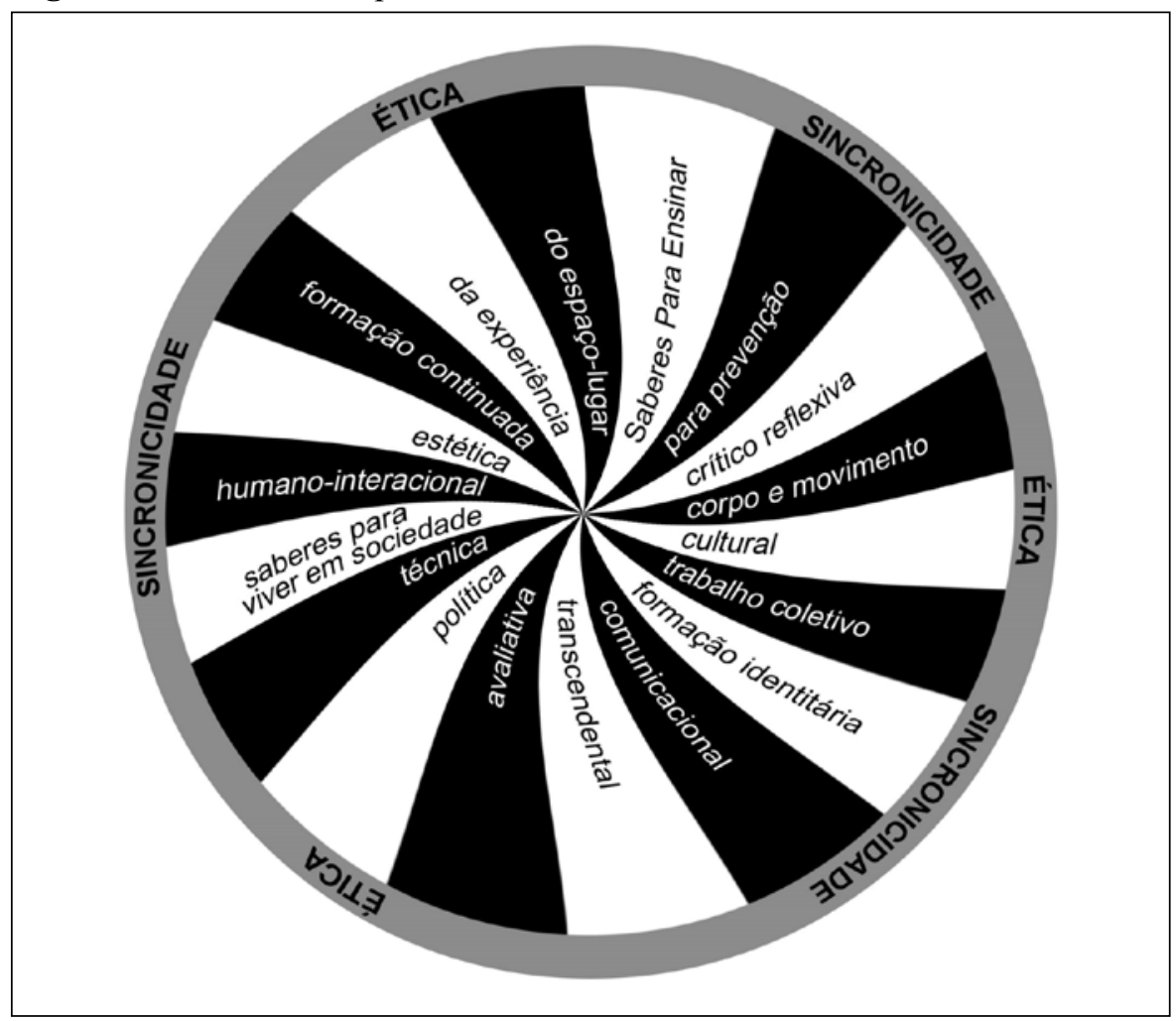

Fonte: Placco (2014)

Tais dimensões, identificadas como fundamentais para a atuação do professor, do coordenador pedagógico e dos gestores educacionais, serão descritas a seguir. Considera-se que muitas dimensões são de tal forma articuladas entre si, que apresentá-las de forma separada permite pensar em uma formação fragmentada. Por outro lado, não dar realce a cada uma delas poderia obscurecer uma ou outra dimensão. São posições em tudo contrárias o que propomos: que todos os saberes e dimensões devem ser articulados nos processos de formação.

\section{Dimensões técnico-científica e humano-interacional}

A dimensão técnico-científica se refere aos conteúdos, metodologias e técnicas que o professor deve dominar para desenvolver sua área disciplinar em uma escola. No entanto, quando se considera o atual progresso científico e a rapidez com que as mudanças ocorrem nos diferentes campos, fica evidente que não é possível exigir o domínio completo de um campo de conhecimento. Como 
então proceder a seleção dos saberes curriculares que garantam ao professor e a seus futuros alunos o domínio atualizado de determinada área de conhecimento?

A orientação básica que vem sendo proposta pelos educadores (GARCIA, 1999; NÓVOA, 1992; TARDIF; LESSARD, 2005) tem sido a de que seria necessário desenvolver essa formação técnica do ponto de vista de uma formação básica, que garanta os conhecimentos e processos fundamentais na área de conhecimento, de modo a garantir flexibilidade e criatividade do professor para produzir mudanças e ampliações do seu campo conceitual. Além disso, pela própria natureza desses conhecimentos, destaca-se a necessidade da articulação com outros saberes, em uma produção inter, multi e transdisciplinar.

Professores que são formados tendo como prioridade sua formação científica, isto é, considerando com exclusividade as teorias e experimentos relacionados à sua área, no momento em que se defrontam com a sala de aula, nem sempre conseguem traduzir tais saberes em ofertas de situações de aprendizagem que possibilitem o acesso dos alunos a esse conhecimento. É neste momento que se passa a exigir que os professores tenham uma formação em outra dimensão - a dos saberes para ensinar, que afinal deveria ter sido adquirida no momento de sua formação inicial ou nos MPs.

Acredita-se que quando a formação considera apenas os aspectos cognitivos, dá-se conta de apenas parte da tarefa de formação do professor. É preciso compreender que a formação integral do professor envolve uma formação humana que reflita e tenha impacto sobre sua vida pessoal e profissional, seu comportamento, suas relações e suas atitudes. Significa subsumir os aspectos interacionais, as relações com o outro. Implica compreender que "somente sou professor porque tenho aluno" e que, portanto, o aluno é constituidor de minha profissionalidade.

A dimensão humano-interacional envolve também considerar o corpo e o movimento - bem como a comunicação -, que são dimensões da mutualidade da informação, da compreensão e afetos entre os sujeitos, da identidade e da alteridade, em processo de troca contínua.
$\mathrm{O}$ professor precisa estar à vontade com o próprio corpo e com seus movimentos, enquanto dimensão fundamental. Sua espontaneidade em sala de aula ocorre na medida do crescimento de suas relações de confiança quanto a si mesmo, aos alunos, ao seu trabalho. Esta é uma dimensão negligenciada e até mesmo ignorada nas ações formativas empreendidas nas escolas e nos sistemas de ensino.

Os saberes da comunicação, enquanto parte da formação humano-interacional, envolvem as habilidades comunicacionais do professor, os aspectos interpessoais e sociais dessa comunicação (CATELLANI, 2013). Aprende-se a viver em sociedade simultaneamente à aprendizagem da comunicação. Como professores, é fundamental aprender a se comunicar com os alunos que pertençam a outras gerações, com experiências pessoais, culturais e socioeconômicas diferentes. Saber com quem estou falando - criança, adolescente, adulto -, saber que tipos de experiências e disposições têm aqueles com quem convivo, saber as necessidades e expectativas de aprendizagem daqueles a quem me proponho ensinar são exigências do viver em sociedade e da comunicação. O professor, na comunicação e na relação de diálogo que estabelece com suas palavras, seus gestos, seu corpo, seu espírito, dá sentido às informações que quer fazer chegar aos alunos.

\section{Dimensão da formação continuada}

A busca fecunda de outros saberes, que levem o professor a viver a docência em um movimento contínuo de aperfeiçoamento, é um processo a ser ensinado em cursos de formação e MPs.

Se compreendemos o valor indiscutível dos conhecimentos técnico-científicos, se reconhecemos, na sociedade atual, o rápido desenvolvimento de todas as áreas, entendemos que o profissional egresso das instituições formadoras não pode sentir terminada sua formação. Na realidade, se não continuar acompanhando os progressos havidos em sua área, se não continuar estudando, pesquisando, questionando sua área de conhecimento, buscando novas informações, analisando-as e incorporando-as à sua formação básica, sua prática em sala de aula será rapidamente ultrapassada, seus conhe- 
cimentos restarão obsoletos, seus conhecimentos serão questionados por alunos e pares.

Para evitar isso, o professor terá que estudar e pesquisar continuamente. Além disso, se sua formação the ofereceu sólidas bases em sua área - flexibilidade e criatividade, aliadas à atitude de busca -, o professor aprenderá a gerar, em si e por si, interesse e motivação para prosseguir e buscar processos de formação continuada. Assim, este será um processo que se estenderá como um processo de inquietação contínua com o já conhecido e uma busca do novo e diferenciado em sua vida profissional. E o mais importante a considerar: que esta inquietação, esta busca contínua é uma habilidade que pode ser ensinada e deve ser objeto de currículo de formação do professor. Para tanto, é preciso que a forma de contrato do professor e as condições nas quais assume a docência devam prever situações de formação continuada na escola e fora dela. A formação continuada na escola exige que as equipes de gestão (coordenadores pedagógicos e diretores) incluam eles mesmos, em suas tarefas, processos de aprofundamento da docência, que podem se realizar na própria escola ou em cursos de especialização.

\section{Dimensão do trabalho coletivo e da construção coletiva do projeto pedagógico - formação como prevenção}

O trabalho do professor envolve um trabalho integrado e cooperativo, fruto de um processo de formação intencionalmente elaborado e mediado pelas relações socioafetivas e cognitivas.

A escola atual tem, na perspectiva e exigência do trabalho coletivo, o contraponto à menor eficácia de um trabalho isolado por parte do professor. Inicia-se com o projeto político-pedagógico, que é indicativo de uma proposta da escola, em que os objetivos de formação do aluno estão explicitados. Para sua consecução, faz-se necessário que professores e gestores se organizem em torno dele, com um trabalho sistemático e intencionado. Esse deve ser um trabalhar cooperativo, integrado e solidário, dado que voltado para objetivos comuns. É um processo que expressa o compromisso com a formação do aluno e com o próprio desenvolvimento profissional do professor.
Do ponto de vista da dimensão coletiva do e no trabalho docente, há necessidade da explicitação do pedagógico e construção de espaços alternativos para que a interação dos professores se concretize enquanto projeto pessoal e institucional. Não deve ser fruto de iniciativas individualizadas, mas de um projeto político-pedagógico-institucional (PLACCO, 2008).

Dadas as condições de trabalho do professor, da qualidade de sua formação, e da complexidade que constitui a atividade docente, enfatizamos a importância e o significado da atuação e formação coletiva do professor. Um outro aspecto precisa ser enfatizado: a situação de vulnerabilidade dos professores, dos alunos e das escolas, faz-se necessário estabelecer aproximações entre formar e educar e prevenir, isto é, a atuação dos professores e gestores (coordenador pedagógico e diretor) deve-se pautar pelo pressuposto de que a prevenção é esperada, na escola, na direção de preparar alunos e educadores para escolhas mais conscientes, parta o enfrentamento dos desafios cotidianos, dentro e fora da escola.

Esse enfrentamento nos leva a introduzir a dimensão do espaço-lugar, isto é, as características do espaço da escola - onde se localiza, o perfil socioeconômico dos alunos e professores, os índices de vulnerabilidade social e desigualdade presentes, as relações que os profissionais da escola estabelecem entre si, com os alunos, destes entre si e da comunidade escolar consigo e com a escola - atravessam a formação do professor (PEREIRA, 2015) e a impregnam significativamente.

\section{Dimensão Ética e Política, que define os fins da educação e que se sustenta na transcendência do sujeito}

O professor precisa ter uma visão de Educação do ser humano que pretende formar e para que sociedade. Educador é um projeto que se realiza no futuro. Para que futuro? Em que direção?

Compreender sua realidade, a realidade da escola e buscar a formação de um ser humano, para um desejado tipo de sociedade, faz do professor um artífice do futuro. Sem esta perspectiva, o professor se transforma em um profissional sem esperança, engolido pelo cotidiano do fazer, deixa de assumir 
a crítica que o faz esperançoso e político. Como afirma Paulo Freire (1992, p. 1) em Pedagogia da Esperança: “A esperança é necessidade ontológica; a desesperança, esperança que, perdendo o endereço, se torna distorção da necessidade ontológica."

Para reconstruir a esperança, é necessário que o professor aprenda a conhecer seus alunos, sua origem social, suas experiências prévias, seus conhecimentos anteriores, sua capacidade de aprender, sua inserção na sociedade, suas expectativas e necessidades. Reconstruir a esperança exige que o professor assuma o projeto político-pedagógico da escola e as necessidades educacionais da sociedade, as políticas públicas, o mercado e o mundo do trabalho.

Formar professores sem levá-los a conhecer o sentido de sua profissão, sem aprender a conhecer seus alunos, é conduzi-los a uma formação desesperançosa.

Essa dimensão se caracteriza como política e se articula com a ética. Sintetiza os valores e ideais expressos nos conhecimentos e relações que dão direção e intencionalidade à vida e à ação do sujeito. Concretiza-se quando o professor assume um compromisso ético com a realidade social e educacional, quando tem a percepção do seu papel social e do seu aluno.

Nesse sentido, essa dimensão leva em consideração também a espiritualidade do sujeito, sua ligação com aquilo que é percebido como maior que ele, o sentido que ele atribui à sua vida e à do outro. É uma dimensão que evidencia como se é guiada pelo valor do transcendental, o que significa dar importância e considerar o sentido da vida para cada pessoa, de maneira que se identifica aí seu compromisso com o trabalho, com a educação, com os alunos, com a escola. Não se trata de uma dimensão religiosa, mas destaca-se a necessidade de se ter consciência do sentido da vida para si e para a sociedade, como constituintes do ser professor. Daí considerar-se a importância de que ela esteja presente nos momentos de formação, pois, como destacam Berger e Luckmann (2004), a crise de sentido que nossa sociedade vive atualmente faz com que a busca de sentido, nas diversas comunidades de convivência do ser humano, seja uma necessidade urgente, pois esse sentido se estabelece e se explicita por meio dessas relações e da consciência delas. Essa preocupação com o sentido da vida afeta o sujeito, afeta o outro com que convive, afeta a sociedade, transforma as relações e confere significado às experiências que vivem uns com os outros.

\section{Dimensões cultural e estética - reconhece e valoriza a história pessoal e profissional do sujeito, entrelaçada à história de sua cultura e de sua comunidade, de modo a permitir-lhe descobrir-se nessa realidade. Esse universo simbólico envolve a ciência, a arte e a religião}

A busca fecunda de outros saberes, de outras áreas, motiva o professor a viver as múltiplas dimensões da vida, da cultura e da busca do sentido da vida. Essas dimensões comumente não são pensadas como objeto da formação, desconsiderando o fato de que o professor que não vive experiências culturais, estéticas e filosóficas dificilmente poderá provocá-las em seus alunos.

Placco (2008, p. 196) aponta que a dimensão estética e cultural tem relação com as "[...] experiências pelas quais o formando se aproxima de sua cultura, desenvolve o senso estético, apura sua capacidade de observação e identifica componentes importantes para sua formação identitária, como pessoa e profissional".

Assim, possibilitar que o professor reflita, sistemática e intencionalmente, sobre sua herança cultural, sobre as expressões culturais e estéticas e sobre as ideias filosóficas de seu país, sobre o desenvolvimento das letras e das artes, da história das ciências e das tecnologias, no Brasil e no mundo, permeados pelo seu sentido de vida, permitirá a este professor aproximar-se, e ao aluno, do sentido de pertencimento a esse mundo e do próprio sentido de sua vida.

\section{Dimensão avaliativa e crítico-reflexiva}

Em todas as dimensões que consideramos para a formação, a dimensão avaliativa está presente e faz-se necessária: se o professor não consegue estabelecer critérios consistentes de julgamento em relação à sua prática, se não estabelece indi- 
cadores claros em relação aos objetivos que tem em mente, seja em relação à sua disciplina, seja em relação ao projeto político da escola, seja em relação à educação, se não desenvolve uma atitude de pesquisa e curiosidade em relação à sua ação, não terá condições de identificar tanto seus sucessos como suas dificuldades e obstáculos que impedem o êxito de suas ações pedagógicas.

A dimensão crítico-reflexiva reafirma a importância da formação profissional do docente que se assente no "desenvolvimento de reflexão metacognitiva, que implica conhecimento sobre o próprio funcionamento cognitivo pessoal, e habilidade de autorregulação deste funcionamento" (GATTI, 2000 , p. 92), fundamental para e em qualquer processo formativo. Esta dimensão envolve processos metacognitivos, pensar sobre nossos pensamentos e também sobre o nosso agir e sentir.

Pensar crítico, que envolve questionar as origens e os significados de nossos princípios e valores, de nossas certezas e confianças, de nossos saberes e conhecimentos, que envolve projetar as consequências de nossas ações e de nossas opções em um amplo espectro de dimensões de nossa vida profissional e pessoal. (PLACCO, 2008, p. 195).

\section{Dimensões-síntese}

Embora tenhamos afirmado que as dimensões se engendram profundamente na formação e no trabalho docente, sendo sua separação apenas um recurso didático de compreensão e de realce quanto à sua pertinência e importância, consideramos as duas dimensões que se seguem como síntese de nossas reflexões sobre formação: a da experiência e a da formação identitária.

A dimensão da experiência envolve o valor e a necessidade do resgate, da valorização e da reflexão das experiências docentes para a própria formação profissional do professor e mesmo para sua formação identitária (tomada de consciência dos próprios processos experienciais), para o desenvolvimento de sua profissionalidade.

Experiência é tudo aquilo que, ao acontecer, toca em algum aspecto do indivíduo, o faz pensar, sentir diferentemente. Fundamentalmente, a experiência acontece quando o indivíduo se sente mobilizado a agir, a buscar compreender melhor sua vida, sua prática, os outros. São situações para as quais os formadores devem chamar atenção dos formandos, para que a leitura que façam de suas experiências lhes possibilitem ter outro olhar para a profissão, para sua prática, para os outros, para si mesmos. Esta dimensão surgiu dos estudos de uma mestranda (SIGALLA, 2012), cujo trabalho revelou a grande importância atribuída pelos professores à sua experiência profissional, seja no campo da educação, seja em outras áreas do conhecimento. Em decorrência dessa discussão, a dimensão da experiência foi descrita como a necessidade do resgate, a valorização e a reflexão sobre as experiências docentes para a própria formação profissional do professor e mesmo para sua formação identitária (tomada de consciência dos próprios processos experienciais).

Uma das características mais fortes dos processos de formação docente que temos observado se refere à não consideração das experiências docentes dos professores. Estes, ao participarem de processos formativos, trazem consigo suas experiências prévias com a docência, sejam as que se referem ao seu prévio estatuto de aluno, sejam às ligadas ao seu ofício docente, recente ou passado. No entanto, os processos formativos ignoram essa experiência, embora os professores relatem a influência recebida de seus antigos professores ou das experiências diretas com as salas de aula. Sua visão da prática, ou seja, a experiência em sala de aula, se refere a algo que realmente conhecem, porque vivenciaram aquilo de alguma forma. A interpretação que deram a muitas situações concretas nem sempre é a mais adequada ou à luz dos fundamentos teóricos mais recentes, o que implica na necessidade de processos formativos que, partindo dessa concretude, a ela voltem, num movimento em espiral, a partir de processos formativos intencionais e planejados.

Assim, poder mostrar sua experiência profissional e pô-la à prova em confronto com a teoria permite aos professores pensar e transformar as habilidades desenvolvidas em experiências profissionais prévias.

A dimensão da formação identitária parte da premissa de que cada pessoa constrói e reconstrói sua identidade, nas ações e relações de sua vida e, portanto, essas reconstruções acontecem também ao longo de sua formação. Nesse sentido, essa 
dimensão pode ser considerada quase uma síntese das demais, pois, na verdade, refere-se à constituição do ser humano, quando há um processo formativo em andamento. A formação identitária se traduz na constituição do profissional, por meio das identificações que ele assume a partir das atribuições que lhe são imputadas pelo sistema, pela escola, pela gestão, pelos pares, por pais e alunos e por si mesmo.

Entendendo, como propõe Dubar (2005), que a constituição identitária de cada pessoa se dá na negociação entre o que lhe é atribuído por outros e aquilo a que adere ou com o que identifica como sua pertença, identificamos a importância de esta dimensão ser cuidadosamente considerada nos processos formativos, especialmente nos MPs. O professor, ao viver o cotidiano da escola, recebe inúmeras e variadas demandas e atribuições, assim como a pressão de suas próprias necessidades e expectativas. $\mathrm{Na}$ medida em que as recebe, essas atribuições terão o potencial de se constituir em pertenças, constitutivas da sua formação identitária. Além do mais, dado que a instituição escola é constituída pelos seus sujeitos, a identidade profissional dos professores contribui para a formação da identidade institucional, em decorrência das relações que se estabelecem entre eles: assim, as atribuições feitas aos professores e por eles assumidas voltam para a instituição como elementos constitutivos da identidade institucional. É um movimento dinâmico de negociações identitárias, pessoais, profissionais e institucionais, influenciado pelas configurações históricas e culturais de cada momento e pelos processos formativos desencadeados.

No entanto, muito frequentemente, o professor busca responder a atribuições diversas, originadas de fontes diversas, sem a devida reflexão e escolha de sua parte. Assim, o processo formativo pode ser o instrumento a partir do qual esses processos de identificação e não identificação e essas negociações se tornam conscientes e possibilitam escolhas reais e fundamentadas.

Temos afirmado que a dimensão ética atravessa todas as outras, envolvendo valores, atitudes, compromissos, desejos, intencionalidades e ações (PLACCO, 2006, 2008).
Chamamos atenção para o fato de que, por estarem sincronicamente presentes no ser humano, se estas dimensões não forem deliberadamente incluídas nos processos formativos, sua formação ocorrerá mesmo assim - e de forma aleatória e não focada -, o que impossibilitará ao formador e formando lhes darem sentido e direção.

Chamamos ainda atenção para o fato de que a formação do professor em todas essas dimensões precisa estar entendida na perspectiva colaborativa da formação, isto é, na perspectiva da parceria entre os professores, entre professores e gestores, em que todos se reúnam em torno da corresponsabilização pela aprendizagem dos alunos e pela qualidade de ensino, na escola e no país.

\section{Considerações}

Considerando que um dos principais desafios dos Mestrados Profissionais é a interpretação que venham a fazer das necessidades do contexto educacional, entendemos que a compreensão que seus propositores tenham desse contexto é fundamental para a definição de suas propostas. Assim, muitas perspectivas são possíveis nessas proposições, dada a diversidade e a complexidade das necessidades da educação brasileira. Nesse sentido, é fundamental que as propostas de mestrado profissional levem em conta os diagnósticos do sistema de ensino, especialmente as avaliações externas nacionais, como SAEB e Prova Brasil, e as estaduais, realizadas pelas secretarias de educação, que ampliam nossa compreensão da realidade da educação básica. Além disso, fazem parte desses diagnósticos as pesquisas sobre a realidade educacional brasileira e suas demandas, que também possibilitam informações importantes para as propostas de MP.

Um segundo desafio apresentado neste texto, que se refere às necessidades e proposições teóricas quanto à formação de professores que respondam às demandas identificadas na realidade brasileira, traz reflexões decorrentes de longa experiência de formadoras das autoras. Afirma-se aqui a necessidade da formação de professores em múltiplas dimensões, o que influenciará diretamente o desempenho de suas funções e seu desenvolvimento profissional. O MP, portanto, ao propor a formação e o desenvolvimento de um profissional da educação - seja 
ele professor, gestor ou coordenador pedagógico - , não pode desconhecer a sincronicidade dessas dimensões e considerar o processo de formação apenas ancorado em uma ou algumas delas.

\section{REFERÊNCIAS}

BERGER, P.; LUCKMANN, T. Modernidade, pluralismo e crise de sentido. São Paulo: Vozes, 2004.

CATELLANI, G. V. O professor e a comunicação na sala de aula - importância atribuída à formação didático pedagógica e às técnicas de comunicação em sala de aula, por estudantes de pós-graduação que tem interesse em lecionar no ensino superior. 2013. 223f. Dissertação (Mestrado em Educação - Psicologia da Educação) - Pontifícia Universidade Católica de São Paulo, São Paulo, 2013.

DUBAR, C. A socialização: construção das identidades sociais e profissionais. Porto: Porto Editora, 2005. (Coleção Ciências da Educação).

FREIRE, Paulo. Pedagogia da esperança: um reencontro com a pedagogia do oprimido. Rio de Janeiro: Paz e Terra, 1992.

GARCIA, G. M. Formação de professores: para uma mudança educativa. Porto: Porto Editora, 1999.

GATTI, B. A. Os professores e suas identidades: o desvelamento da heterogeneidade. Cadernos de Pesquisa, São Paulo, n. 98, p. 85-90, ago. 1996.

Formação de professores e carreira: problemas e movimentos de renovação. 2. ed. Campinas, SP: Autores Associados, 2000.

GATTI, B. A.; BARRETO, E. S. S.; ANDRÉ, M. E. D. A. Políticas docentes no Brasil: um estado da arte. Brasília: UNESCO, 2011.

NÓVOA, A. (Org.). Os professores e sua formação. Lisboa: Dom Quixote, 1992.

OLIVEIRA, R. M. M. A. de. Narrativas: contribuições para a formação de professores, para as práticas pedagógicas e para a pesquisa em educação. Revista de Educação Pública, Cuiabá, v. 20, n. 43, p. 289-305, 2011.

PEREIRA, R. Entre aspirações, quereres e fazeres: nas trilhas do desenvolvimento profissional de um grupo de coordenadores pedagógicos iniciantes. São Paulo, 2015. Mimeografado.

PERRENOUD, P. Práticas pedagógicas, profissão docente e formação. Lisboa: Dom Quixote, 1993.

PINEAU, G. Temporalidade e formação. São Paulo: Trion, 2004.

PLACCO, V. M. N. de S. Formação e prática do educador e do orientador. 5. ed. Campinas, SP: Papirus, 2002a.

Formação de professores: o espaço de atuação do coordenador pedagógico-educacional. In: FERREIRA, N. S. C.; AGUIAR, M. A. (Org.). Para onde vão a orientação e a supervisão educacionais? Campinas, SP: Papirus, 2002b. p. 95-106.

Relações interpessoais em sala de aula e desenvolvimento pessoal de aluno e professor. In: ALMEIDA, L. R.; PLACCO, V. M. N. de S. As relações interpessoais na formação de professores. São Paulo: Loyola, $2002 c$. p. 7-19.

Perspectivas e dimensões da formação e do trabalho do professor. In: SILVA, A. M. M. et al. Educação formal e não-formal, processos formativos, saberes pedagógicos: desafios para a inclusão social. Recife: Bagaço, 2006. p.

. Processos multidimensionais na formação de professores. In: OLIVEIRA, L. E.; ARAÚJO, M. I. O. Desafios da formação de professores para o século XXI: o que deve ser ensinado? O que é aprendido? Aracaju: Editora Universidade Federal de Sergipe, 2008. p. 185-198.

. A aprendizagem do adulto-professor: desafios ao coordenador pedagógico como formador. IV Congresso Brasileiro Psicologia: Ciência e Profissão. São Paulo: Editora. do Evento, 2014. v. 1.

SANTOS, A. P. R. dos. Imagem do professor e atratividade da docência: enunciados sobre carreira docente na mídia impressa. Revista da FAAEBA: Educação e Contemporaneidade, Salvador, v. 23, n. 42, p. 197-206, 2014 
SIGALLA, L. A. A. De profissional a profissional-professor: contribuições para a formação de professores universitários da área de Administração. 2012. 112f. Dissertação (Mestrado em Educação) - Pontifícia Universidade Católica de São Paulo, São Paulo, 2012.

SOUSA, C. P. et al. Dificuldades dos alunos do $5^{\circ}$ ano do Ensino Fundamental em Matemática. Estudos em Avaliação Educacional, v. 23, p. 198-221, 2012.

SCHÖN, D. Formar professores como profissionais reflexivos. In: NÓVOA, A. (Org.). Os professores e a sua formação. Lisboa: Dom Quixote, 1992. p. 15-33.

TARDIF, M., LESSARD, C. O trabalho docente: elementos para uma teoria da docência como profissão de interações humanas. Petrópolis, RJ: Vozes, 2005.

Recebido em: 01/03/2016

Aprovado em: 20/04/2016 